Case report

https://www.journal-imab-bg.org

\title{
ZOLEDRONATE-ASSOCIATED RECURRENCE OF OSTEONECROSIS OF JAWS
}

\author{
Rosen Tsolov ${ }^{1}$, Elena Firkova ${ }^{2}$, Georgi Yordanov ${ }^{3}$, Silvia Tzvetkova-Trichkova ${ }^{4}$ \\ 1) Department of Maxillofacial and Oral surgery, Saint George Hospital \\ University Medical Center, Plovdiv, Bulgaria. \\ 2) Department of Periodontology and Oral Diseases, Faculty of Dental \\ Medicine, Medical University - Plovdiv, Bulgaria. \\ 3) Department of Oral Surgery, Faculty of Dental Medicine, Medical University \\ - Plovdiv, Bulgaria. \\ 4) Diagnostic Consulting Center, Saint George Hospital University Medical \\ Center, Plovdiv, Bulgaria.
}

\begin{abstract}
Medication-related osteonecrosis of the jaws is a commonly reported complication in patients receiving antiresorptive medications. We report a case of bone necrosis followed by comparatively fast recurrence in a patient with intravenous administration of zoledronic acid. The purpose is to focus the attention of dental practitioners on the possibility of recurrence and the importance of regular check-ups since preventive measures today are one of the most important management strategies for patients treated with zoledronate.
\end{abstract}

Keywords: medication related osteonecrosis, zoledronate, recurrence

The incidence of medication-related osteonecrosis of the jaw (MRONJ)is constantly increasing.

Currently, there are three groups of drugs, related directly to MRONJ - bisphosphonates, denosumab and antiangiogenic drugs. This complication, though still relatively rare, adversely affects the quality of life of the affected patients, producing significant morbidity.

MRONJ is diagnosedwhen all the four criteria are fulfilled: (1) a history of administration of a bone resorption orangiogenesis inhibitors; (2) bone in the maxillofacial region exposed persistently for more than eight weeks; (3) no history of radiation therapy to the jaw; (4) absence of malignancy in the involved region [1].

Pathophysiologic mechanisms of MRONJ development are not quite clear, although the first case was reported almost 20 years ago by Marx [2]. Currently, there are three main hypotheses proposed for the pathogenesis of MRONJ:

1. Suppressed bone turnover $[3,4]$;

2. Direct cellular toxicity $[5,6]$;

3. Infection, immune system abnormalities and accumulation of microfractures $[7,8,9]$.

Zoledronic acid (Zometa®; Reclast, Novartis Pharmaceuticals) was approved in 2002. At this time, the only severe side effects were hypocaliemia and renal deteriora- tion in patients with renal insufficiency. Only 1 year after the approval, the first evidence that zoledronate is linked to osteonecrosis was reported [2].

In Bulgaria, zoledronate is mostly used. It is the most potent inhibitor of all bisphosphonates which reduce bone resorption and osteoblast activity, which leads to the accumulation of microdamages and areas of necrosis $[10,11]$. Its cytotoxic effect on bone cells, epithelial cells and macrophages leads to disruption of the integrity of the oral mucosa, infection and subsequently - lack of wound healing [12].

Epidemiologic data has revealed that more potent bisphosphonates, more frequent dosing, a higher cumulative dose and a longer duration of treatment are the major risk factors for the osteonecrosis. Systemic risk factors include the aforementioned, but also the presence of diabetes and other immunocompromising diseases; genetic factors and age [13].

Dentoalveolar surgery is considered to be the major local risk factor for developing MRONJ. Tooth extraction is the most common event, proved to be the initiating factor of MRONJ in almost $60 \%$ of patients [14]. Pre-existing periodontal diseases is a risk factor in almost half of the patients [15]. It is proved by clinical parameters, serum immunoglobulin $\mathrm{G}$ titers against Porphyromonasgingivalis and interleukin-1â, demonstrating that periodontitis and associated bacteria are important in the pathogenesis of MRONJ [16].

The risk of MRONJ in cancer patients on zoledronate therapy is approximately 1\% (100 cases per 10,000 patients). Almost the same is the risk for patients on RANKL inhibiting treatment with denosumab. Intraoral administration of bisphosphonates for osteoporosis represents a smaller risk factor, compared to intravenous administration. The duration of medication administration continues to be a significant risk factor. The incidence of developing MRONJ among cancer patients exposed to zoledronate or denosumabis increasing with time - respectively $0,5 \%$ at 1 st year, $1 \%$ at 2 nd year and $1,3 \%$ at $3 \mathrm{~d}$ year [17]. 
Factors affecting the recurrence of MRONJ are not well elucidated. Probably the type and duration of administered medication are most important, together with the presence of bacterial infections in the affected area, methods of treatment used (conservative or surgical, including primary closure of secondary healing cases) [18].

Treatment strategies recommended by the guidelines of the American Association of Oral and Maxillofacial surgeons are based on the symptoms and progression of the disease. Conservative treatment includes pain control, antibiotics and antibacterial rinses. Surgical treatment is performed to remove the necrotic bone and soft tissue. Adjunctive treatment options areteriparatide; bone morphogenetic proteins, platelet concentrates and platelet-derived growth factors, low level laser therapy, hyperbaric oxygenation, medical ozone therapy [19]

The purpose of the present clinical case of MRONJ is to focus on the possibility of recurrence that could be really fast in some cases. Knowledge and awareness among dentists and medical doctors for preventive measures are one of the most effective management strategies for patients treated with zoledronate.

\section{CASE PRESENTATION}

A 72 years old male patient was referred to the maxillofacial clinic with symptoms of a non-healing lesion in the area of right posterior mandible. Detailed medical history revealed that the patient was diagnosed with multiple myeloma and bone metastases in 2010. Since then he was treated with intravenous administration of zoledronate with periods of drug holidays. The main complaint of the patient was pain, which was radiating to the temporomandibular joint and discomfort while eating. No other symptoms were reported. There was no dental procedure before the development of the lesion that could initiate the necrosis. Intraoral examination revealed soft tissue destruction in the edentulous area of the right posterior mandible, with exposed necrotic alveolar bone and signs of local inflammation in the site of necrosis (fig. 1).

Fig. 1. Clinical appearance of the edentulous lower right quadrant, with visible necrotic bone on the alveolar ridge.

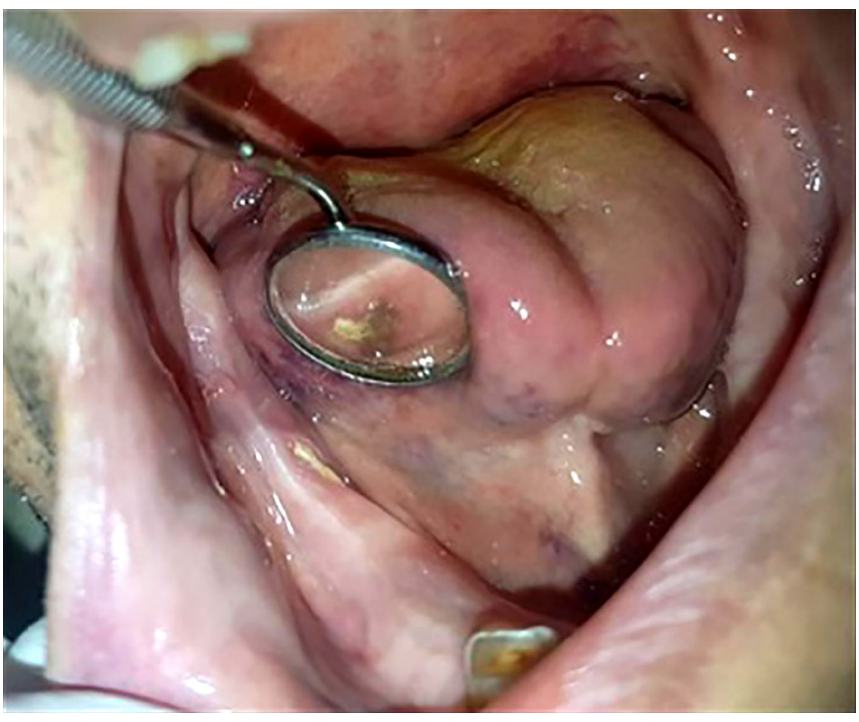

Computer tomography revealed big radiotranslucent area in the right mandible, with dense woven bone osteosclerosis of the surrounding bone (fig. 2).

Fig. 2. Computer tomography of the affected mandible.

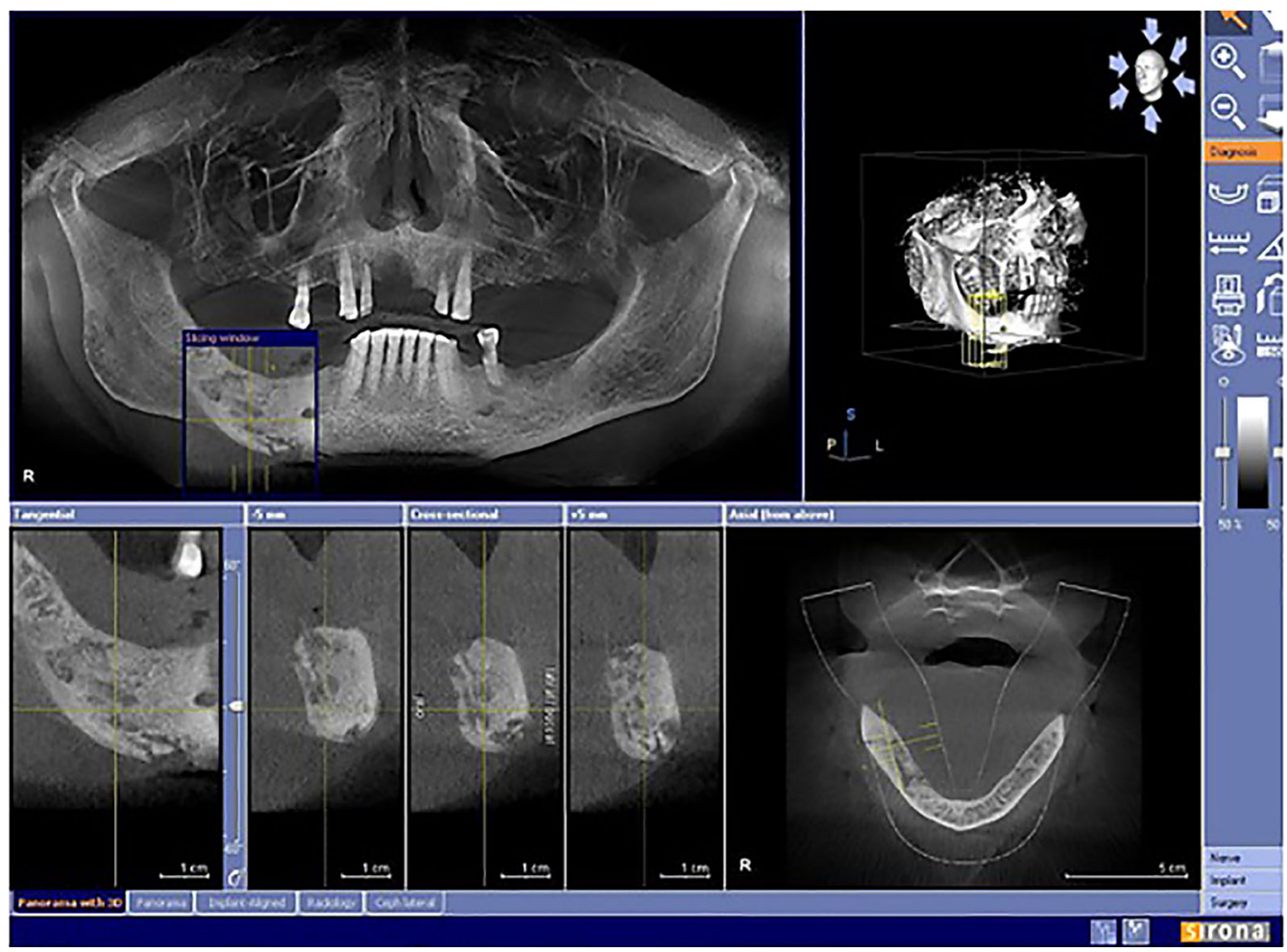


The patient was diagnosed with MRONJ stage 2 according to the staging system and criteria of the American association of oral and maxillofacial surgeons.

Conservative periodontal treatment was performed to reduce the inflammation and reduce the bacterial load on the remaining teeth. Then the surgical treatment was done. It consisted of complete removal of the necrotic mandible and osteoplasty of residual bone margins (fig. 3).

Fig. 3. Surgical intervention, consisting of full thickness flap elevation and thorough bone debridement

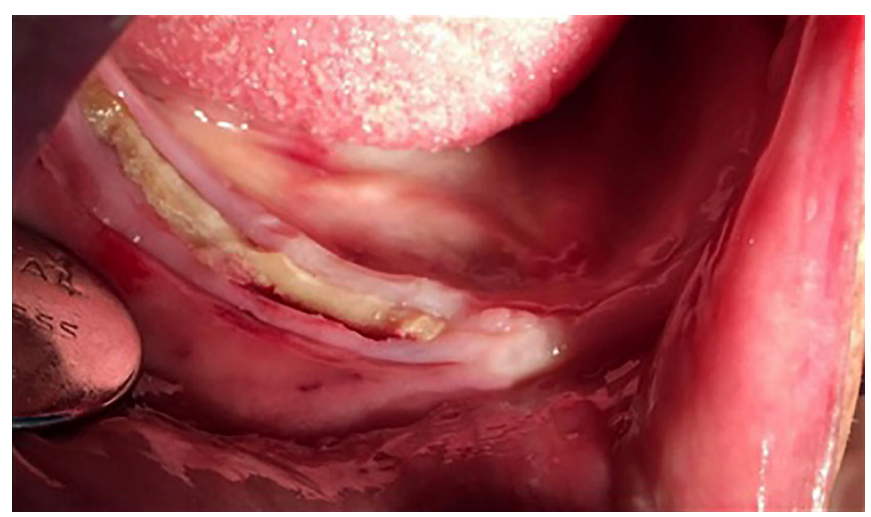

Platelet-rich fibrin membranes were used to stimulatethe healing process in the alveolar bone and soft tissues and reduce the wound healing time (fig. 4).

Fig. 4. Application of a membrane of platelet-rich fibrin with stimulating growth factors

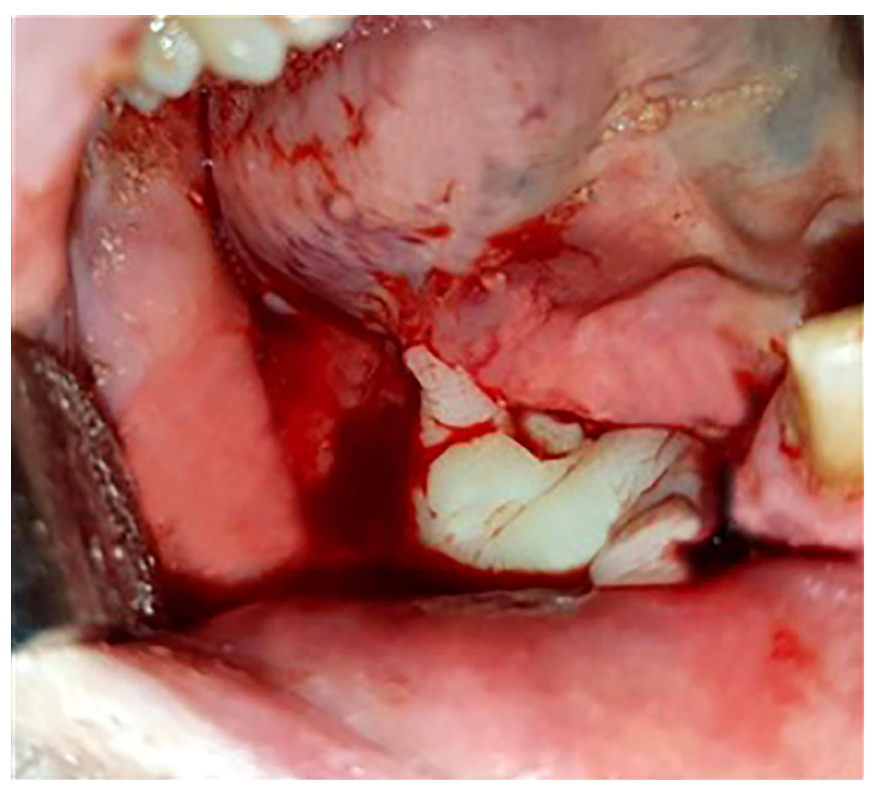

A combination of ceftriaxone ( $1 \mathrm{~g} /$ day i.v.) and metronidazole (1,5 g/day) was administered for 1 week to cover the most common bacteria. The recovery went uneventful (fig. 5).
Fig. 5. Clinical view of the area at the 1-month follow-up

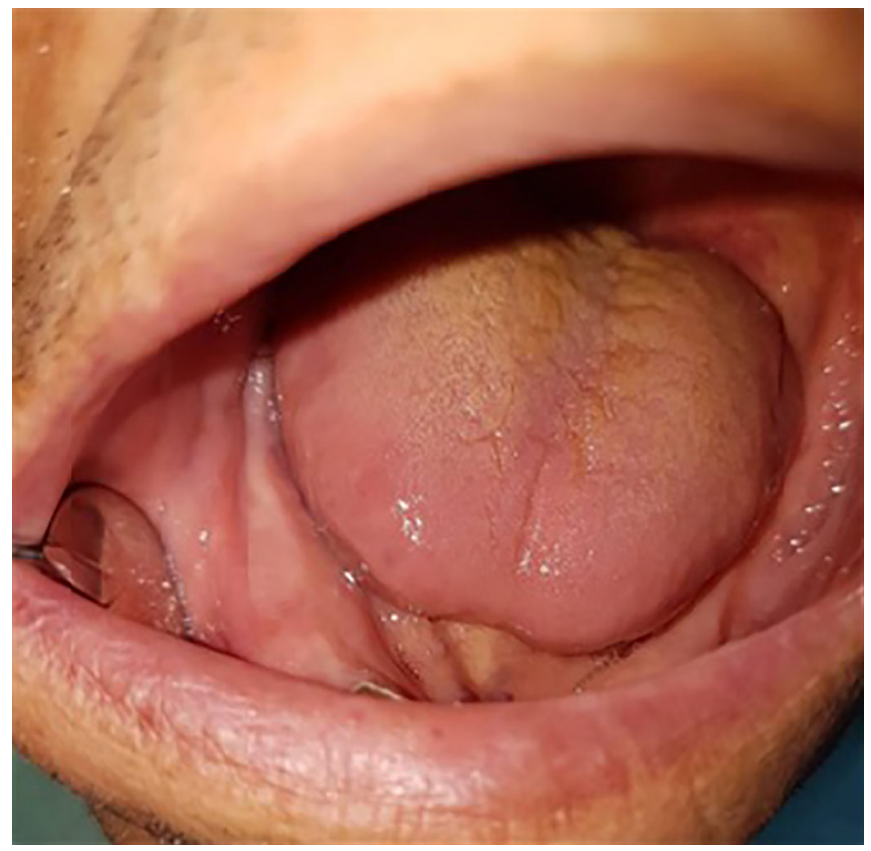

The patient was followed-up each month.

6 months later, the patient came to the routine follow-up with the same complaints again, this time from the anterior maxilla. The intraoral and radiographic examination revealed a recurrence of the osteonecrosis, located in the anterior maxillary right area (fig. 6, 7).

Fig. 6. Clinical appearance of the new necrotic bone lesion in the maxillary anterior area

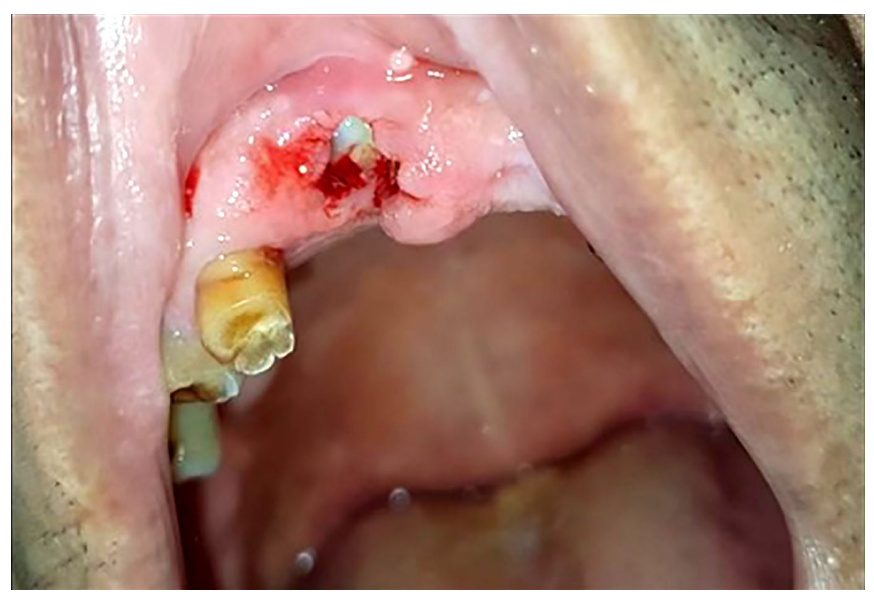


Fig. 7. Computer tomography of the affected anterior maxilla. Necrotic bone is clearly demarcated.

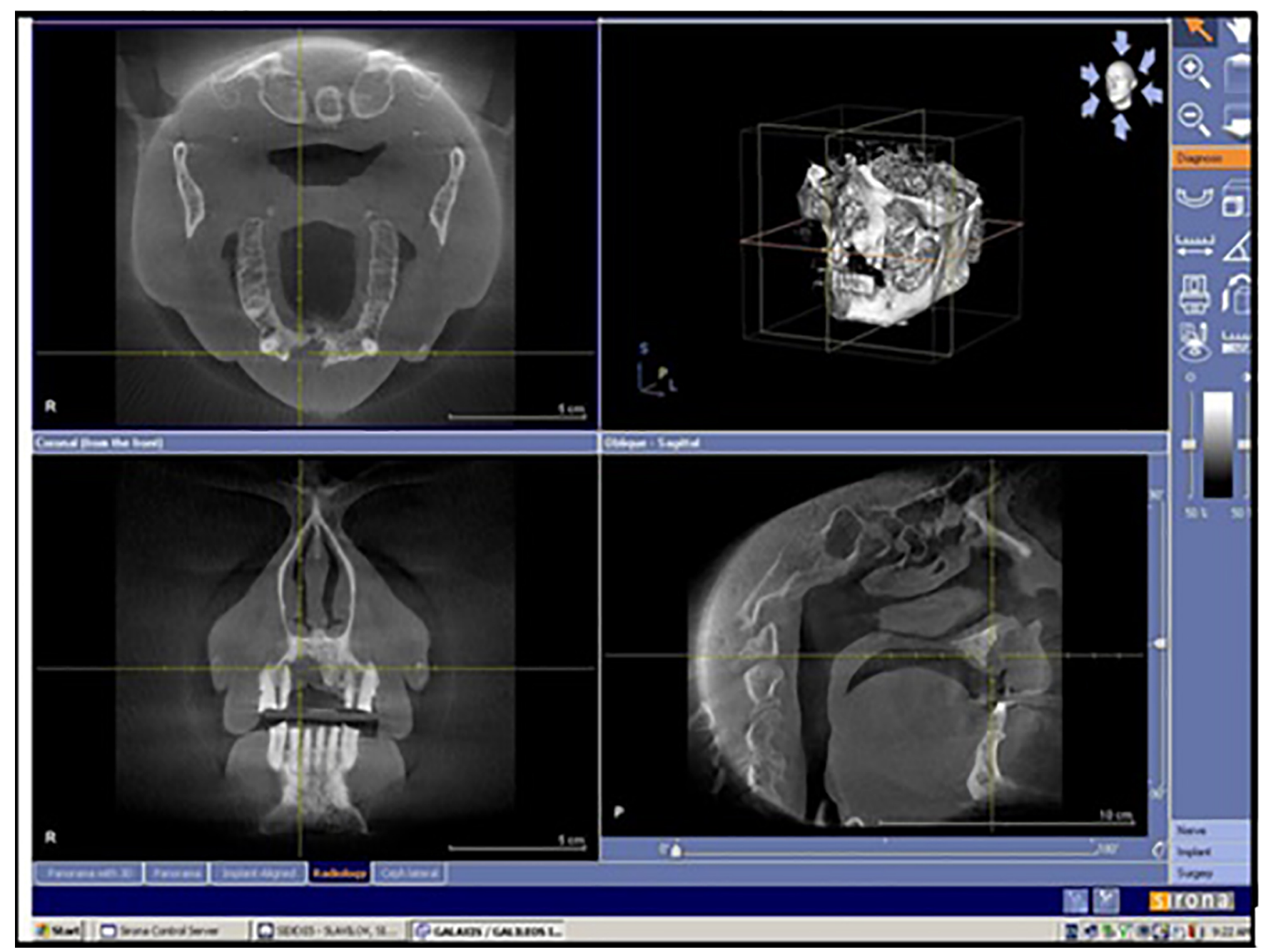

The same treatment (conservative and surgical) was performed.

\section{DISCUSSION}

Currently, it is not clear whether treatment with bisphosphonates should be stopped or proceeded in the presence of MRONJ. Watters et al. reported a long term follow up of 109 patients with MRONJ. $48 \%$ of them stopped i.v. bisphosphonate treatment, but there was no statistical difference in the clinical course of osteonecrosis in them, compared to those patients who did not stop the treatment [19].

Based on our surgical experience and that of others, surgical procedures should be planned and performed early in the course of management of MRONJ. It has been demonstrated that in the advanced stages 2 and 3, nonsurgical approaches are not effective in more than 50\% of the cases. Surgical intervention, especially when combined with biologically active agents like platelet con- centrates, result in resolution of MRONJ, even when the patient developed recurrence of the osteonecrosis.

In order to reduce the possibility of MRONJ development and recurrence of the condition, later each patient should be evaluated individually, considering the medical history, systemic diseases, and clinical symptoms. Incidence of MRONJ may be reduced through appropriate drug holiday and/or alternative treatment.

\section{CONCLUSION}

We expect that dentists will increasingly encounter patients undergoing antiresorptive/antiangiogenic treatment, with the possibility of developing MRONJ. Currently, zoledronic acid is often used in Bulgaria. Being one of the most potent bisphosphonates, practitioners be able to anticipate the potential complication of this medication and be aware of the possibility of recurrence of the osteonecrosis that maybe sometimes fast. 


\section{REFERENCES:}

1. Ruggiero SL, Dodson TB, Fantasia J, Goodday R, Aqhaloo T, Mehrotra $\mathrm{B}$, et al. American association of oral and maxillofacial surgeons position paper on medication-related osteonecrosis of the jaw - 2014 update. J Oral Maxillofac Surg.2014 Oct;72(10): 1938-56. [PubMed]

2. Marx RE. Pamidronate (Aredia) and zoledronate (Zometa) in-duced avascular necrosis of the jaws: a growing epidemic. J Oral Maxillofac Surg. 2003 Sep;61(9):1115-7. [PubMed]

3. Landesberg R, Woo V, Cremers S, Cozin M, Marolt D, Vunjak-Novakovic $\mathrm{G}$, et al. Potential pathophysiological mechanisms in osteonecrosis of the jaw. Ann N Y Acad Sci. 2011 Feb;1218:6279. [PubMed]

4. Baron R, Ferrari S, Russell RG. Denosumab and bisphosphonates: different mechanisms of action and effects. Bone. 2011 Apr 1;48(4):677-92. [PubMed]

5. Cornish J, Bava U, Callon KE, Bai J, Naot D, Reid IR. Bone-bound bisphosphonate inhibits growth of adjacent non-bone cells. Bone. 2011 Oct; 49(4):710-6. [PubMed]

6. Rogers MJ, Chilton KM, Coxon FP, Lawry J, Smith MO, Suri S. Bisphosphonates induce apoptosis in mouse macrophage-like cells in vitro by a nitric oxide-independent mechanism. J Bone Miner Res. 1996 Oct; 11(10):1482-91. [PubMed]

7. Hoefert S, Schmitz I, Tannapfel A, Eufinger H. Importance of microcracks in etiology of bisphosphonaterelated osteonecrosis of the jaw: a possible pathogenetic model of symptomatic and non-symptomatic osteo- necrosis of the jaw based on scanning electron microscopy findings. Clin Oral Investig. 2010 Jun;14(3):271-84. [PubMed]

8. Pazianas M. Osteonecrosis of the jaw and the role of macrophages. $J$ Natl Cancer Inst. 2011 Feb 2;103(3): 232-40. [PubMed]

9. Reid IR, Bolland MJ, Grey AB. Is bisphosphonate-associated osteonecrosis of the jaw caused by soft tissue toxicity? Bone. 2007 Sep;41(3): 318-320. [PubMed]

10. Lombard T, Neirinckx V, Rogister B, Gilon Y, Wislet S. Medication-related osteonecrosis of the Jaw: new insights into molecular mechanisms and cellular therapeutic approaches. Stem Cells Int. 2016; 2016: 8768162. [PubMed]

11. Khan AA, Morrison A, Hanley DA, Felsenberg D, McCauley LK, O'Ryan F, et al. Diagnosis and management of osteonecrosis of trhe jaw: a systematic review and international consensus. J Bone Min Res. 2015 Jan; 30(1):3-23. [PubMed]

12. Landesberg $\mathrm{R}$, Cozin $\mathrm{M}$, Cremers S, Woo V, Kousteni S, Sinha S, et al. Inhibition of oral mucosal cell wound healing by bisphosphonates. $J$ Oral MaxillofacSurg. 2008 May; 66(5):839-847. [PubMed]

13. Vahtsevanos K, Kyrgidis A, Verrou E, Katodritou E, Triaridis S, Andreadis CG, et al. Longitudinal cohort study of risk factors in cancer patients of bisphosphonate-related osteonecrosis of the jaw. J Clin Oncol. 2009 Nov 10;27(32):5356-62. [PubMed]

14. Scoletta M, Arata V, Arduino
PG, Arduino PG, Lerda E, Chiecchio A, et al. Tooth extractions in intra-venous bisphosphonate-treated patients: a refined protocol. J Oral Maxillofac Surg. 2013 Jun;71(6):994-9. [PubMed]

15. Saad F, Brown JE, Van Poznak C, Ibrahim T, Stemmer SM, Stopeck AT, et al. Incidence, risk factors, and outcomes of osteonecrosis of the jaw: integrated analysis from three blinded active-controlled phase III trials in cancer patients with bone metastases. Ann Oncol. 2012 May;23(5):1341-7. [PubMed]

16. Tsao C, Darby I, Ebeling PR, Walsh K, O'Brien-Simpson N, Reynolds $\mathrm{E}$, et al. Oral health risk factors for bisphosphonate-associated jaw osteonecrosis. J Oral Maxillofac Surg. 2013 Aug;71(8):1360-6. [PubMed]

17. Otto S, Pautke C, Van den Wyngaert T, Niepel D, Schiodt M. Medication-related osteonecrosis of the jaw: prevention, diagnosis and management in patients with cancer and bone metastases. Cancer Treat Rev.2018 Sep; 69:177-187. [PubMed]

18. Mong-Hun K, Dong-Keon L, Chang-Woo K, In-Seok S, Sang-Ho J. Clinical characteristics and recurrencerelated factors of medication-related osteonecrosis of the jaw. J Korean Assoc Oral Maxillofac Surg. 2018 Oct; 44(5):225-231. [PubMed]

19. Watters AL, Hansen HJ, Williams T, Chou JF, Riedel E, Halpern J, et al. Intravenous bisphosphonate-related osteonecrosis of the jaw: Long-term follow-up of 109 patients. Oral Surg Oral Med Oral Pathol Oral Radiol. 2013 Feb;115(2):192-200. [PubMed]

Please cite this article as: Tsolov R, Firkova E, Yordanov G, Tzvetkova-Trichkova S. Zoledronate-associated recurrence of osteonecrosis of jaws. J of IMAB. 2020 Oct-Dec;26(4):3348-3352. DOI: https://doi.org/10.5272/jimab.2020264.3348

\author{
Address for correspondence: \\ Rosen Tsolov \\ Department of Maxillo-facial and Oral surgery, Saint George Hospital University \\ Medical Center, \\ 66 ,PeshterskoShoseblvd., Plovdiv, Bulgaria \\ E-mail: dr.rosentsolov@gmail.com,
}

